\title{
PROPOSTA DE IMPLEMENTAÇÃO DA MELHORIA MÉTODO PDCA PARA A DOS PROCESSOS NO CONTROLE DE ESTOQUE: ESTUDO DE CASO NA EMPRESA IBTECH ASSISTÊNCIA TÉCNICA
}

\section{ARTIGO ORIGINAL}

SILVA, Lara Mirele Farias da ${ }^{1}$

BORGES, Patrícia Gomes ${ }^{2}$

SILVA, Roberta Farias da ${ }^{3}$

ROBERTO, José Carlos Alves ${ }^{4}$

SILVA, Lara Mirele Farias da. Et al. Proposta de implementação da melhoria método PDCA para a dos processos no controle de estoque: estudo de caso na empresa Ibtech Assistência Técnica. Revista Científica Multidisciplinar Núcleo do Conhecimento. Ano 05, Ed. 11, Vol. 22, pp. 37-56. Novembro de 2020. ISSN: 24480959, Link de acesso:https://www.nucleodoconhecimento.com.br/administracao/melhoria-metodopdca

\section{RESUMO}

O presente artigo teve como objetivo geral identificar e compreender elementos que contribuem para o aumento de nível de serviço e satisfação do cliente. Buscou também avaliar os canais de distribuição e controle de estoque, a fim de ajudar a empresa nas informações sobre seus pontos fracos, a partir da ferramenta PDCA usando a $5 \mathrm{~W} 2 \mathrm{H}$ para auxiliar nas qualidades das operações, verificando de que forma

\footnotetext{
${ }^{1}$ Graduação em Administração.

2 Graduação em Administração.

${ }^{3}$ Graduação em Administração.

${ }^{4}$ Orientador. Mestre em Engenharia de Produção.
} 
a ferramenta poderá contribuir para a melhoria dos processos. $\mathrm{O}$ trabalho teve como finalidade um estudo de caso com abordagem de implementação na melhoria dos processos de controle de estoque através da ferramenta PDCA. O projeto surgiu através dos estudos na organização e das áreas funcionais, onde os pontos críticos foram em operações e destacou-se a falta de controle no estoque. A metodologia foi através de estudo exploratório, realizado através de coleta de dados, levantamento de dados, entrevistas, análise documental, e lavamento de dados por meio de questionários.

Palavras-chave Controle, estoques, armazenagem.

\section{INTRODUÇÃO}

A eficiência na distribuição tem reflexos no bom desempenho competitivo da empresa, pois as falhas nas operações com a falta de equipamentos no estoque causam atraso na venda, na entrega de mercadorias, bem como também para realizar seus serviços.

Ao analisar o cenário da empresa lbetch identificou-se a área de Operações como ponto mais crítico da empresa. No entanto, buscou-se por meio de levantamento de hipóteses sobre quais seriam os meios para resolução das causas como sendo: perdas e desvios de produtos devido a negligência no controle de estoque; e peças que retornavam com defeito para o estoque ao invés de voltar para os fornecedores, ocasionando atrasos e perdas financeiras.

Desta forma, a lbetch necessita implementar as ferramentas PDCA e 5W2H para agregar valor em suas operações e conferir quem são os principais intermediários que levam o produto até o consumidor, afim de registrar de maneira organizada e bem planejada, para que sejam executadas as ações operacionais, tais como: por quem, quando e onde, por que e quanto irá custar para empresa.

Em geral, os preços dos produtos são elevados por se tratar de uma empresa que engloba dois intermediadores: o distribuidor e varejista, que levam ao destino final, e que precisa levar da melhor maneira para seus consumidores e garantir a satisfação 
do cliente. Além disso, conta com o auxílio dos métodos 5 S para a melhor organização do espaço e também experiência no trabalho para os colaboradores.

Assim, o presente artigo teve como objetivo identificar e compreender elementos que contribuem para o aumento de nível de serviço e satisfação do cliente. Determinar os principais canais de distribuição onde os fabricantes e produtores tem que oferecer sua mercadoria no menor tempo possível. Analisar questionários e pesquisas de satisfação do consumidor final.

\section{REFERENCIAL BIBLIOGRÁFICO}

O referencial bibliográfico é a comprovação da teoria que dará suporte a pesquisa. No referencial, o pesquisador registra informações, citações, sempre com relação a formulação do problema. Deve ser escrito de forma coerente, apresentando citações diretas e indiretas e as análises dos autores referente a pesquisa.

A finalidade da pesquisa científica não é apenas um relatório ou descrição de fatos levantados empiricamente, mas o desenvolvimento de caráter interpretativo, no que se refere aos dados obtidos. É imprescindível correlacionar a pesquisa com o universo teórico, optandose por um modelo teórico que sirva de embasamento à interpretação do significado dos dados e fatos colhidos ou levantados. Todo projeto de pesquisa deve conter premissas ou pressupostos teóricos sobre os quais o pesquisador (o coordenador e os principais elementos de sua equipe) fundamentará sua interpretação estruturalista.

Diante do exposto, o referencial bibliográfico serve para dar fundamento as ideias dos autores, referências para a pesquisa, conceitos envolvidos com o tema, sendo abordados dados necessários para percepção do modelo de gerenciamento de canais de distribuição e controle de estoque.

\subsection{CANAIS DE DISTRIBUIÇÃO}

Um fator importante para qualidade dos produtos e serviços da empresa é a definição do canal de distribuição logística, pois entende-se o quanto é relevante ter o local certo, e disponibilizar a quantidade de produtos ideal para conseguir captar novos clientes. 
Os canais de distribuição são as formas que uma empresa fabricante decide entregar seus produtos ao consumidor final.

Um dos grandes problemas respectivos das operações de frotas no transporte de cargas é o de coleta e distribuição, pois a falta de planejamento e de um sistema prático dificulta o desempenho nas operações. (VALENTE, 2020).

\subsubsection{CANAIS DE DISTRIBUIÇÃO: A INSERÇÃO DO SISTEMA NA EMPRESA.}

Iniciou-se um estudo de caso empregando a ferramenta PDCA com base nos dados fornecidos pela empresa. Os problemas encontrados serviram de base para estudo, com a finalidade de reduzir ou até mesmo eliminá-los.

A falta de componentes no estoque causa atrasos para a entrega do produto para o consumidor final. Para obter melhorias na empresa a inserção do sistema permitiu enxergar os graves problemas da distribuição e no controle de estoque.

O estoque caracteriza-se por um armazenamento de recursos materiais distribuídos em um sistema de transformação. Cada tipo de operação mantêm um estoque, onde todas as operações produtivas possuem diversos tipos de materiais armazenados e/ou estocados.

Deste modo, a administração de estoques propõe-se em elevar o controle de custos e melhorar a qualidade dos produtos armazenados na empresa. Comumente as teorias sobre este tema advertem que é possível determinar uma ótima quantidade de estoque de cada componente e produtos da empresa, partindo da previsão da demanda de consumo dos produtos. (DIAS, 2016).

\subsubsection{A EVOLUÇÃO DOS CANAIS DE DISTRIBUIÇÃO NO TEMPO}

Os canais de distribuição crescem se adequando as mudanças ambientais. A evolução da estrutura dos canais de distribuição requer uma evolução similar nas estruturas logísticas dos fornecedores. 
Toda maneira é essencial para refletir sobre as rotinas diárias de produção para evitar problemas no controle, gerando consequências no inventário, que ocasionam despesas para empresa. O controle de estoque é o método utilizado para protocolar, fiscalizar e gerenciar a entrada e saída de mercadorias e produtos tanto na fábrica como no comércio. (VIANA, 2015).

\subsubsection{CANAIS DE DISTRIBUIÇÃO: IMPORTÂNCIA}

Os canais de distribuição são de suma importância para a organização. Eles possibilitam que os produtos da empresa cheguem a um grande número de consumidores. Sendo assim, os produtores que geralmente não têm sua própria rede de distribuição, fazem contratos com terceiros para poder ter um alcance geográfico mais rentável.

Utilizando os meios de canais de distribuição, um fabricante alcança seus objetivos que é oferecer seus produtos em lugares certos e no menor tempo possível, chegando no consumidor final.

Atualmente as formas pelas quais os clientes desejam receber os produtos estão crescendo muito rápido. É preciso dedicar um tempo para examinar a estratégia de canal de distribuição, pois o crescimento constante no mercado faz com que seu padrão de negócio esteja atrasado, estando atrasado implica na otimização para as mudanças no mercado. (ARAÚJO, 2020).

\subsubsection{AS FUNÇÕES DOS CANAIS DE DISTRIBUIÇÃO}

Os canais de distribuição têm como principal função fazer com que o produto chegue de maneira ágil ao local determinado para os consumidores encontrá-lo. Em função disso, existem alguns tipos de estratégias muito utilizadas pelas organizações, dentre as quais se destacam:

Sistema de distribuição direta: A venda é realizada sem intermediários, o fabricante comercializa e distribui os produtos diretos para os consumidores finais. A venda direta e o marketing são as principais variedades de distribuição direta. 
Sistema de distribuição exclusiva: Nesse sistema o fabricante define seus revendedores, consentindo a distribuir de maneira exclusiva os produtos gerenciando grande parte das operações dos revendedores. Nesse sistema, o fabricante vende por meio de um ou poucos negociadores. Normalmente, esse sistema é utilizado quando a organização precisa de fidelidade do distribuidor.

Sistema de distribuição intensiva: Coloca o produto em maiores números de pontos de venda é conveniente para produtos de grande consumo e preços baixos. Os pontos de venda devem ser atingidos por equipes dos próprios fabricantes ou por representantes comerciais. Muitas organizações têm suas esquipes próprias para atender grandes varejistas como hipermercado. Outra parte do varejo é atendida por atacadistas e representantes comerciais.

\subsubsection{OS CANAIS DE DISTRIBUIÇÃO E A LOGÍSTICA DENTRO DO PROCESSO DE GESTÃO DE ESTRATÉGICA DE MARKETING}

Uma vez que o canal de distribuição é definido, a empresa precisa identificar os caminhos que os produtos devem seguir, para adaptar-se da melhor forma às estruturas logísticas de vendas. O principal intuito é disponibilizar produtos nos locais propícios para que o consumidor obtenha de forma ágil, prático e sem dificuldade.

A falta de uma distribuição suficiente e satisfatória, especialmente quanto a peças de reposição e serviço pós-venda tem um forte impacto sobre a venda de bens duráveis. O sistema de distribuição é uma das principais causas de formação da imagem e reconhecimento da qualidade da marca da empresa.

Assim afirma Dornier (2012, p. 308):

Os canais de distribuição estão enfrentando um processo interessante de reestruturação, com uma tendência para a consolidação de poder de mercado com um punhado de mega varejistas. As tendências de mercado mudam os canais e padrões de distribuição para todas as empresas ao longo do tempo. 
Observando o cotidiano da empresa, não há como não analisar a relevância de se tornar uma distribuição de excelência.

Nota-se que, sem isso, o trabalho e serviço prestados ao consumidor podem ser em vão, afetando, assim, o marketing da empresa.

\subsubsection{NÍVEIS DE CANAIS DE DISTRIBUIÇÃO}

A quantidade de intermediários envolvidos nesse processo, será o que vai definir os níveis do canal de distribuição. Os tipos são:

Canal nível 0 - É o momento que o fabricante irá se aproximar inteiramente com seu consumidor final.

Canal nível 1 - Nesse canal, o fabricante venderá o seu produto para um grande distribuidor. Essa operação acontecerá no mercado de varejo, onde poderá alcançar o consumidor final.

Canal nível 2 - A indústria passará o produto à um distribuidor que venderá somente para o varejo. Desta forma, o varejo irá executar a venda ao consumidor.

Canal nível 3 - É o canal mais habitual. Envolverá quatro níveis: distribuidor, representante, varejo e cliente.

\section{MATERIAIS E METÓDOS}

A pesquisa requer um avanço de conhecimento com algo que possivelmente já existia, para obter informações que vão servir de apoio para o planejamento com os melhores métodos e ferramentas, assim será possível atribuir informações e conclusões, garantindo bases solidas. Se respeitarmos a classificação definida por Liane (2013) a metodologia é a ciência que estuda os métodos mais apropriados para a transferência do conhecimento. Metodologia cientifica da pesquisa abrange estufo profundo e crítico dos métodos de pesquisa. Deste modo utilizou diferentes ferramentas adequadas para a empresa Ibtech. 


\subsection{PROCEDIMENTOS METODOLÓGICOS}

Os procedimentos metodológicos são a classificação da pesquisa para definir o método e a forma da pesquisa. Este estudo foi realizado por meio de processos de classificação que permitiram usar ferramentas e tecnologias nas operações da empresa lbtetch.

A pesquisa bibliográfica necessita de tempo disponível para alcançar os objetivos do próprio trabalho; precisa adotar um critério formal transpondo duas situações começar sempre do mais geral para o individual e do mais novo para o mais antigo observando claramente, o caso dos documentos exemplares. (SEVERINO, 2013).

\subsubsection{QUANTO À NATUREZA}

Quanto à natureza possui abordagens e caráter, são obtidos em entrevistas com funcionários com a gerência, e observando os atrasos nos serviços, assim tendo conhecimentos sobre os métodos da organização e o controle de estoque. Gil definiu a base necessária para a pesquisa pode ser qualificada e de avaliação e diagnostico, de avaliação: Acrescenta valor ao caso estudado. No entanto, precisa de critério bem estabelecido de semelhanças ou referencias. É capaz de ter seus fundamentos nos seus procedimentos ou nos resultados. A pesquisa aplicada é oferecida a geração de aprendizado para resolução de problemas inerentes, é averiguado a verdade para estipular a aplicação pratica em condição individual.

\subsubsection{QUANTO AOS FINS}

Quanto aos fins da pesquisa, foi exploratória por ter contato direto com o objeto de investigação e então, conectar as ideias e os fatores.

Os tipos de pesquisa podem ser definidos por dois critérios básicos: quanto aos fins e quanto aos meios.

De acordo com Vergara (2015, p. 31) quanto aos fins a pesquisa pode ser: 
Exploratória: Que é realizada em áreas de pouco conhecimento sistematizado, assim sendo não comporta hipóteses na sua fase inicial, porém no decorrer da pesquisa estas poderão surgir naturalmente.

descritiva: É aquela que expõe características claras e bem delineadas de determinada população ou fenômeno, para isso envolve técnicas padronizadas e bem estruturadas de coletas de seus dados.

Explicativa: Tem como principal objetivo tornar as ações estudadas em dados de fácil compreensão, justificando e explicando os seus principais motivos e o "porquê" das coisas.

metodológica: Está associada aos caminhos, formas, maneiras e procedimentos utilizados para atingir determinado fim. e) aplicada: Tem necessidade de resolver problemas que já existem na prática. De forma imediata ou não.

f) intervencionista: Não se satisfaz apenas na explicação do que se está sendo estudado, mas pretende interferir de alguma forma na realidade, no dia a dia do seu objeto de pesquisa.

Para elaboração dos textos da pesquisa foi utilizado através de artigos científicos, análise documental, questionários e entrevistas, entre outros.

\subsubsection{QUANTO AOS MEIOS}

O artigo teve como base a pesquisa de campo, com observação, coleta, análise e interpretação dos dados, além do documental com objetivo de chegar a construção de uma proposta de determinado assunto. Segundo Vergara (2015, p.47) quanto aos meios de investigação, uma pesquisa pode ser:

De campo: Baseia-se pela experiência que se está sendo aplicada na investigação e é realizada exatamente no local onde são observados os fenômenos estudados.

de laboratório: É realizada em local determinado e limitado.

documental: Através de análises em documentos encontrados em órgãos públicos ou privados, ou com pessoas que detenham a guarda destes documentos.

bibliográfica: É aquele realizado com base em material publicado em livros, jornais, revistas, sites na internet, e que sejam disponibilizados ao público em geral. e) Experimental: Investigação empírica na qual o 
pesquisador manipula e controla variáveis independentes e observa os resultados destas manipulações.

Assim sendo, foi possível verificar a importância da Metodologia da Pesquisa e da Produção Científica nos seus mais variados meios e formas de utilização, para através de exames técnicos, científicos, analíticos e sintéticos, servir como instrumento de aquisição e construção de conhecimentos e saberes, formando pensadores que chegam à natureza do problema ou fenômeno com melhores condições de estudálos, explicando-os quando solicitados e modificando-os quando necessário.

\subsection{CARACTERÍSTICAS DA EMPRESA}

A empresa Telecom Comércio Varejista Especializado de Equip. de Telf - EIRELI foi fundada em junho de 2005 por Igor Bulbol, o mesmo é formado em Engenharia Elétrica.

A empresa é dividida em: salão principal para atendimentos aos clientes, escritório, depósito de peças, laboratório técnico, estacionamento para clientes e estacionamento para os funcionários. Iniciou com uma pequena loja no centro da cidade de Manaus, onde atendia apenas serviços de manutenção em equipamentos eletrônicos.

Em 2016 tomaram um novo rumo com experiências nas prestações de serviços, visando melhoria na qualidade de seus serviços e desenvolver uma nova visão estratégica.

$\mathrm{Na}$ sua trajetória de trabalho sempre focou nas qualidades dos serviços e nos preços acessíveis para toda classe social, visando a melhor qualidade nos atendimentos aos seus clientes. Está presente no mercado há quatro anos.

Assim, a classificação dos diferentes portes de empresa considera distintos critérios, visto que essa classificação varia de acordo com as condições gerais do país em que atuam. 
Nessa perspectiva, indústrias que são consideradas pequenas em alguns países podem ser consideradas medianas em outros. (VIEIRA, 2014).

\section{RESULTADOS E DISCUSSÕES}

\subsection{PROPOSTA DE SOLUÇÃO}

É fundamental acentuar que os resultados e discussões apontados no artigo dizem respeito aos tópicos de ideia de uma forma mais breve, em que se buscam respostas para as questões observadas, procurando resultados e melhorias que solucionem os problemas.

Foi feita a pesquisa organizacional na empresa lbtech por meio de avaliações de documentos, visita de campo, entrevistas e conversas com a equipe, assim foi apontada que a área mais crítica está no setor de operações, para ser mais exata na área de comunicação interna.

De acordo com a análise das áreas funcionais foi possível especificar que a organização possui muitas áreas de desempenho baixos e elevadas. Tem como modelo a área de Marketing em que o empreendedor da organização do sistema deve prosseguir ajustando, de modo que a continue gestão eficiente. A área crítica da empresa foi apontada como área de Operações, conforme mostra o Gráfico 1 a seguir.

Gráfico 01 - Desempenho por área funcional 


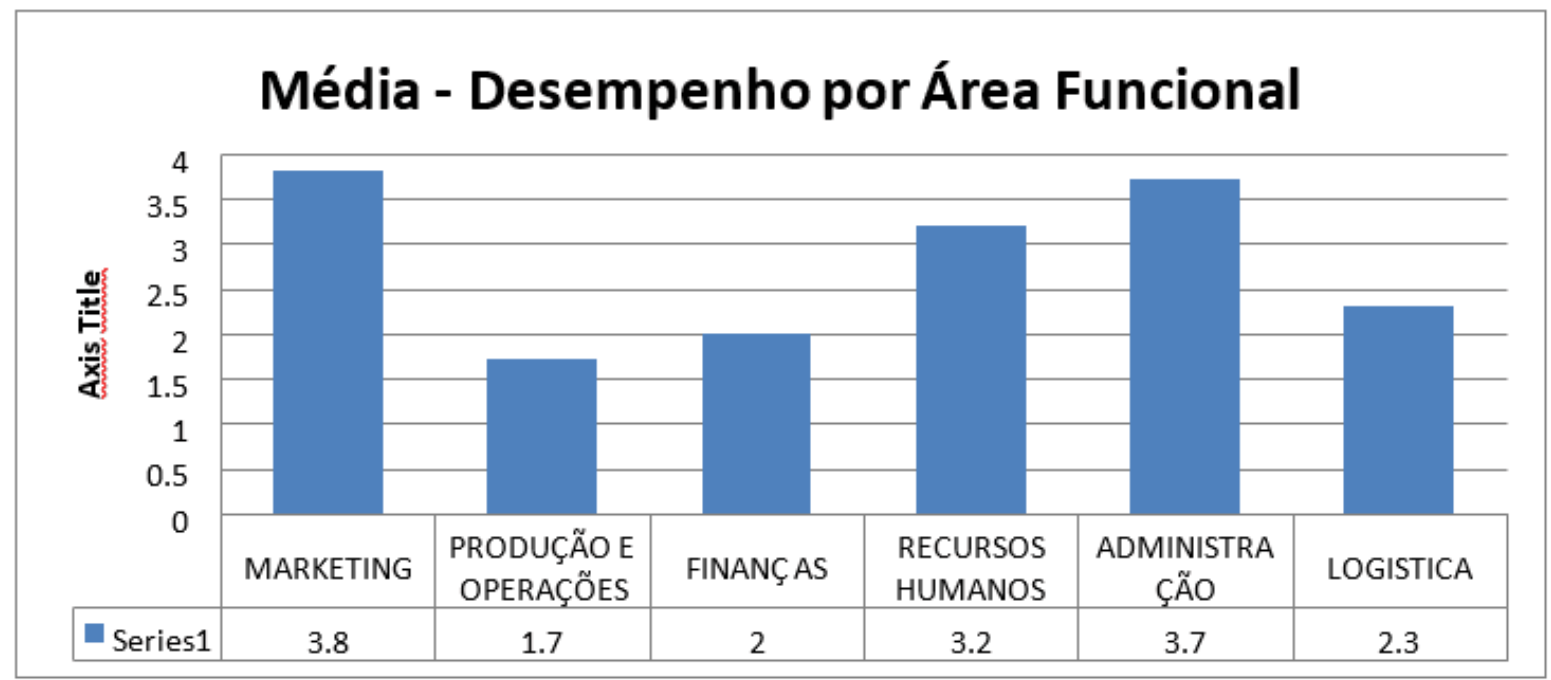

Fonte: Elaborada pela equipe com base em pesquisa de campo, 2020.

Quadro 01 - Quadro de áreas críticas

\begin{tabular}{|c|c|c|c|c|c|c|}
\hline \multicolumn{2}{|c|}{$\begin{array}{l}\text { AREA FUNCIONAL } \\
\end{array}$} & \multicolumn{5}{|c|}{ NIVEL OU GRAU DE AVALIAÇÃo } \\
\hline \multicolumn{2}{|r|}{ OPERAÇÕES } & $\begin{array}{l}\text { Ponto } \\
\text { muito }\end{array}$ & $\begin{array}{l}\text { Ponto } \\
\text { forte }\end{array}$ & $\begin{array}{l}\text { Ponto } \\
\text { médio }\end{array}$ & $\begin{array}{c}\text { Ponto } \\
\text { fraco }\end{array}$ & $\begin{array}{l}\text { Ponto } \\
\text { muito }\end{array}$ \\
\hline 1 & Qualidades nos serviços & & & $\mathrm{x}$ & & \\
\hline 2 & Controle de estoque de peças de reposição & & & & & $x$ \\
\hline 3 & $\begin{array}{l}\text { Espaço disponivel para armazenagem dos } \\
\text { produtos }\end{array}$ & & & & & $\mathrm{x}$ \\
\hline 4 & Estacionamento para os clientes & & & & & $x$ \\
\hline 5 & Organização nas instalações da empresa & & & & & $x$ \\
\hline 6 & Controle dos serviços & & & & $\mathrm{x}$ & \\
\hline 7 & Perdas de serviços por falta de peças em estoque & & & & & $\mathrm{x}$ \\
\hline 8 & Padronizaçăo no serviço prestado & & & & & $\mathrm{x}$ \\
\hline 9 & Usos tecnológicos para favorecer o serviço & & $x$ & & & \\
\hline 10 & Programas de fidelizaçăo & & & & $\mathrm{x}$ & \\
\hline \multicolumn{2}{|c|}{ TOTAL ( $(\Sigma)$} & 0 & 4 & 3 & 4 & 6 \\
\hline \multicolumn{2}{|c|}{ MÉDIA POR GRAU (POR COLUNA) } & 0 & 0,4 & 0,3 & 0,4 & 0,6 \\
\hline \multicolumn{2}{|c|}{ DESEMPENHO DA ÁREA ( } & \multicolumn{5}{|c|}{1,7} \\
\hline
\end{tabular}

Fonte: Elaborado pela equipe com base na pesquisa de campo, 2020.

Por meio de pesquisa no setor de Operações foram observadas algumas fraquezas que cooperam contra a ineficiência. Assim, a empresa tem necessidade de progresso: disciplina dentro da organização, controle de entradas e saídas de materiais, e 
inventário físico nas peças. Por meio desta análise pode-se constatar problemas de eficiência em alcançar resultados e melhorias.

Constatou-se diversos pontos fracos, incluindo monitoramento de estoque de peças como mostrado no quadro abaixo, as quais entram e saem. Foi averiguado por meio de pesquisas da organização, que a empresa porta 1 modelo de software com controle pouco usado, ou seja, uma versão passada que necessita ser atualizada. A falta de controle no estoque prejudica e dificulta o serviço, gerando atrasos na entrega e insatisfação no cliente.

No Quadro 01 - Quadro área mais crítica, observa-se que o indicador 1 - Controle de Estoque, foi apontado como ponto fraco na empresa, pois não existe uma ferramenta que auxilie na organização das entradas e saídas de peças.

Também não existem instalações para atividade de estoque, assim como se pode observar nos indicadores 3 e 5 - Espaço disponível para armazenagem dos produtos e Organização nas instalações da empresa, assim também tendo relação com o indicador 9 - Uso tecnológicos para favorecer o serviço, a falta desse controle de estoque faz com que se perca totalmente o controle de entradas e saídas.

Com base nos indicadores pode-se observar que existe grande problemas em relação ao estoque da empresa, sendo mais específico em seu controle geral. O estudo foi realizado em uma empresa de serviços de manutenção em equipamentos eletrônicos. Por isso, ressalta-se a importância da eficiência e eficácia em seus processos de manutenção, os quais a empresa tenha controle de entrada e saída de seus produtos e peças.

A ferramenta escolhida a ser utilizada foi a ferramenta da qualidade conhecida como "Ciclo PDCA" que, segundo Lima (2020, p. 5) "[...] faz parte de um conjunto de ações estratégicas cujo objetivo é de melhorar a qualidade de produtos e serviços[...]".

Usado como uma forma de melhoria, que auxilia os gestores a encontrarem o método mais adequado de observar e planejar. O desenvolvimento de processos feitos a partir do ciclo PDCA, auxilia na resolução dos problemas da empresa, além de ser um dos 
mais utilizados para essa finalidade. Sendo assim, é usado para encontrar soluções para problemas pouco visíveis e procurar melhorias através do mesmo.

Quadro 02 - Quadro de Proposta de Melhoria

\begin{tabular}{|l|l|}
$\begin{array}{l}\text { Pontos } \\
\text { Negativos }\end{array}$ & Ações de Melhorias \\
\hline $\begin{array}{l}\text { Controle de } \\
\text { estoque e de } \\
\text { reposição de } \\
\text { peças. }\end{array}$ & $\begin{array}{l}\text { Ideia de instalação de sistema para organização e melhoria do } \\
\text { estoque, com finalidade do controle dos matérias que auxiliam } \\
\text { na estocagem, assim o tornando mais eficiente. }\end{array}$ \\
\hline $\begin{array}{l}\text { Organização } \\
\text { nas instalações } \\
\text { da empresa }\end{array}$ & $\begin{array}{l}\text { Planear espaço para organização do estoque, para facilitar a } \\
\text { localização dos produtos. }\end{array}$ \\
\hline $\begin{array}{l}\text { Perdas } \\
\text { serviços } \\
\text { falta de poças } \\
\text { no estoque }\end{array}$ & $\begin{array}{l}\text { Fazer o levantamento das peças que já estão na loja, para que } \\
\text { saiam e não exista perdas. }\end{array}$ \\
\hline $\begin{array}{l}\text { Uso } \\
\text { tecnológicos } \\
\text { para favorecer o } \\
\text { serviço }\end{array}$ & $\begin{array}{l}\text { feito o levantamento do estoque, em forma de inventário, assim } \\
\text { sabendo os produtos disponíveis e o volume de cada um deles, } \\
\text { melhorando, assim, o atendimento ao cliente e atendendo aos } \\
\text { prazos. }\end{array}$ \\
\hline & \\
\hline
\end{tabular}


Fonte: Elaborado pelas autoras com base na pesquisa documental e entrevista, 2020.

No quadro acima pode-se verificar os demonstrativos dos pontos fracos e também as propostas de melhorias feitas para empresa lbtech. Diante disso, foi desenvolvido um projeto de melhoria para avaliar capacidade de construção do estoque da empresa, com o intuito de melhorar, organizar e aumentar o nível da produção.

Feito o mapeamento das áreas críticas da empresa que se focam na área de estoque, foi iniciado planos de melhoria para o mesmo, com objetivo de contornar as falhas causadas pela falta de controle nesse setor.

A ferramenta escolhida para auxiliar nas as ações que serão feitas, foi a 5W2H para ajudar nas melhorias, sendo usada juntamente com a ferramenta escolhida anteriormente, dando complemento as necessidades da empresa, mostrou ser a ferramenta mais adequada para ser utilizada no estudo de caso da organização. Foi escolhida ao demonstrar ser uma ferramenta de fácil implementação, manuseio e que vai de acordo com o quê a empresa precisa no momento.

Figura 1 - Ferramenta 5W2H 


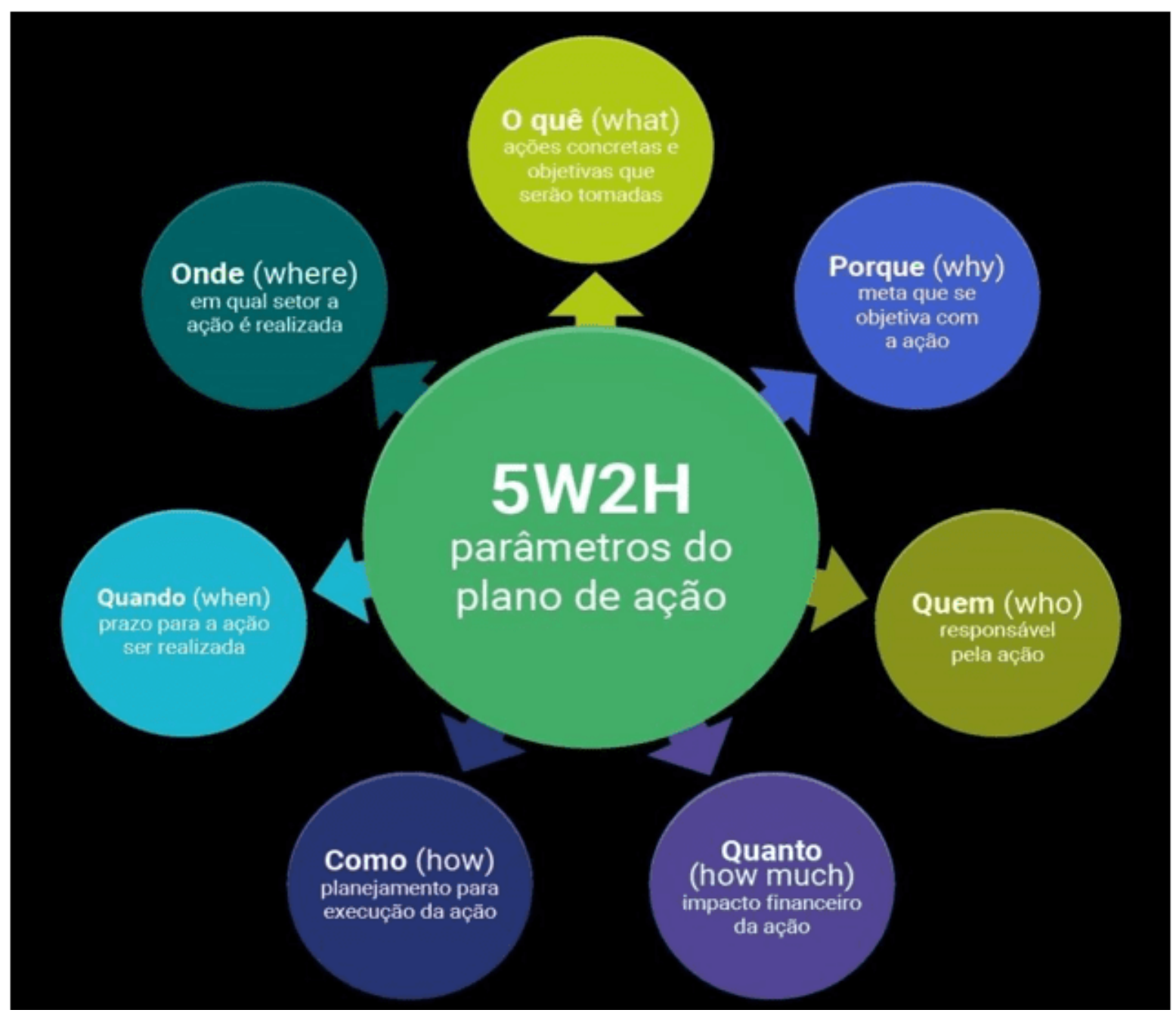

Fonte: https://images.app.goo.gl/1fmLggkGwKs6EQyT8

A ferramenta $5 \mathrm{~W} 2 \mathrm{H}$ foi criada no Japão para auxiliar no planejamento, feita em forma de planilha ou Tabela. Sua metodologia costuma ser utilizada em projetos para avaliar, acompanhar e garantir que as atividades sejam executadas com eficiência e de forma clara, podendo ser uma espécie de guia.

O 5W2H é utilizado para identificação de problemas, podendo apresentar soluções; é uma excelente alternativa para elaborar um plano de ação, não importando a necessidade ou problema. Sendo assim, sua maior característica é ser a solução aplicável em todos os tipos de empresa não importando o seu porte ou área de atuação.

Quadro 03 - Atividades Propostas 


\begin{tabular}{|c|c|c|c|c|}
\hline Item & Atividades & Tempo & Públicoalvo & Custo \\
\hline 01 & $\begin{array}{l}\text { Contratar um profissional para } \\
\text { avaliar os problemas e fazer a } \\
\text { implementação do } 5 \mathrm{~S} \text {. }\end{array}$ & $\begin{array}{l}3 \\
\text { meses }\end{array}$ & $\begin{array}{l}\text { Proprietário/ } \\
\text { Colaborador }\end{array}$ & $\mathrm{R} \$ 6.000,00$ \\
\hline 02 & $\begin{array}{l}\text { Construir espaço para } \\
\text { armazenamento do estoque. }\end{array}$ & $\begin{array}{l}2 \\
\text { Semana } \\
\text { s }\end{array}$ & Proprietário & $\mathrm{R} \$ 4.000,00$ \\
\hline 03 & $\begin{array}{l}\text { Propor a ideia de contratar um } \\
\text { profissional especialmente para } \\
\text { cuidar do controle de estoque. }\end{array}$ & Mensal & $\begin{array}{l}\text { Proprietário/ } \\
\text { Colaborador }\end{array}$ & $\mathrm{R} \$ 1.200,00$ \\
\hline & Total das Atividades Propostas & $\begin{array}{l}150 \\
\text { dias }\end{array}$ & & $R \$ 11.200,00$ \\
\hline
\end{tabular}

Fonte: Elaborado pela equipe, 2020.

Após a análise dos pontos críticos foi feito um plano de ação para cuidar de cada ponto crítico, assim mostrado no quadro 1, portanto trazendo soluções para as falhas.

O quadro de atividades relata que deve ser colocado em prática para que os pontos críticos sejam corrigidos da melhor forma na área de controle de estoque, assim levando novas ideias para o ambiente organizacional da empresa lbtech, atuando na 
melhoria deixe processos de serviços e encontrando meios para serem introduzidos na área de controle de entrada e saídas de insumos. Além de agregar valo a empresa, isso será um gerador de satisfação na hora de entregar o serviço ao cliente também.

Quadro 04 - Problema 1 - Contratar um profissional para a implementação do 5S

\begin{tabular}{|c|c|c|}
\hline \multicolumn{2}{|l|}{ Pergunta } & \multirow{2}{*}{$\begin{array}{l}\text { Descrição } \\
\text { Contratar um profissional com especialização na } \\
\text { ferramenta } 5 \mathrm{~s} \text {. }\end{array}$} \\
\hline WHAT & O que fazer? & \\
\hline WHO & Quem fará? & Proprietário/Colaboradores \\
\hline WHERE & $\begin{array}{l}\text { Onde será } \\
\text { feito? }\end{array}$ & Na própria empresa. \\
\hline WHEN & Quando fazer? & De imediato. \\
\hline WHY & $\begin{array}{l}\text { Por que será } \\
\text { feito? }\end{array}$ & $\begin{array}{l}\text { Para ajudar a organizar a empresa e trazer } \\
\text { conhecimento aos seus colaboradores. }\end{array}$ \\
\hline HOW & Como fazer? & $\begin{array}{l}\text { Mudando os métodos ultrapassados de trabalho que } \\
\text { estão sendo utilizados na organização. }\end{array}$ \\
\hline $\begin{array}{l}\mathrm{HOW} \\
\mathrm{MUCH}\end{array}$ & $\begin{array}{l}\text { Quanto } \\
\text { custará? }\end{array}$ & $\mathrm{R} \$ 6.000,00$ \\
\hline
\end{tabular}

Fonte: Elaborado pelas autoras do projeto, 2020.

Foi possível identificar os pontos críticos da empresa lbtech, levando em consideração as observações feitas na organização, ligadas ao controle de estoque, além da desordem que existe com os materiais. Daí a necessidade de se aplicar a ferramenta 5S para que exista uma melhoria neste setor. Isso ajudará na redução de custos desnecessários e no aumento da produtividade que atualmente demonstra falhas.

O Seiri (arrumação e utilização) pode ser utilizado para separar o que é útil daquilo que não é mais. Quando algo não é mais utilizável, deve ser reaproveitado em outro local ou reciclado. Isso ajuda na identificação dos recursos e não tem nas atividades diárias da organização. 
O Seiton (Organização), pode ser um auxiliar do primeiro, ele vem para ordenar o devido lugar de cada coisa, utilizado para melhorar o ambiente de trabalho fazendo com que ele fique mais eficiente e pronto para a realização do trabalho. Dessa forma, organizando a área de armazenamento e facilitando a identificação dos produtos e equipamentos.

O Seiso (Limpeza) como o nome já diz, vem para manter o ambiente limpo, descartando objetos que não servem mais no estoque, e eliminando tudo aquilo que já não tem necessidade, melhorando a qualidade do ambiente. O Seiketsu (higiene e saúde) também se aplica a isso. Porém, promove a limpeza do corpo e da mente, preservando também o meio de convívio dos colaboradores.

Por fim, tem-se o Shitsuke (disciplina), onde cada um assume sua responsabilidade para conquistar os objetivos e metas, sendo incentivados pelo gestor. Dessa forma, os colaboradores devem se esforçar juntamente com o gestor da empresa para que a implementação do programa gere mudanças reais.

A ferramenta a ser utilizada foi escolhida para trazer melhorias a empresa, já que o programa tem como foco principal a disciplina, tendo em vista que a empresa lbtech não possui a organização adequada, principalmente na área de estoque.

Exemplo da desordem é que muitas vezes os colaboradores não têm noção se tem ou não determinada peça disponível para a manutenção de seus equipamentos.

Levando a um dos problemas sofridos pela organização, que é a falta de alguém para cuidar desta função, tendo total domínio das entradas e saídas dos materiais.

Quadro 05: Problema 2 - Construir espaço para o armazenamento do estoque

\begin{tabular}{|l|l|l|}
\hline & Pergunta & Descrição \\
\hline WHAT & $\begin{array}{l}\text { O que } \\
\text { fazer? }\end{array}$ & \\
& Construção de um espaço para estoque \\
\hline WHO & Quem fará? & Proprietário/Colaborador \\
\hline
\end{tabular}




\begin{tabular}{|l|l|l|}
\hline WHERE & $\begin{array}{l}\text { Onde será } \\
\text { feito? }\end{array}$ & Na própria empresa \\
\hline WHEN & $\begin{array}{l}\text { Quando } \\
\text { fazer? }\end{array}$ & De imediato \\
\hline WHY & $\begin{array}{l}\text { Por que } \\
\text { será feito? }\end{array}$ & $\begin{array}{l}\text { Eliminar perda dos serviços, por falta de peças e } \\
\text { desordem na estocagem }\end{array}$ \\
\hline HOW & $\begin{array}{l}\text { Como } \\
\text { fazer? }\end{array}$ & \begin{tabular}{l} 
Contratar profissionais para realizar a obra \\
\hline QOW
\end{tabular} \\
\begin{tabular}{l|l} 
MUCH \\
custará?
\end{tabular} & $\mathrm{R} \$ 4.000,00$ \\
\hline
\end{tabular}

Fonte: Elaborado pelas autoras do Projeto, 2020.

O principal passo a ser tomado é a criação de um espaço para o estoque da empresa, com o foco na melhoria do controle de estoque, podemos dar início ao projeto que vai solucionar uma das áreas mais críticas da organização, implementando soluções que ajudem na eficiência de entregar o melhor ao cliente.

Quadro 06: Problema 03 - Contratar colaborador para o estoque

\begin{tabular}{|c|c|c|}
\hline \multicolumn{2}{|l|}{ Pergunta } & Descrição \\
\hline WHAT & O que fazer? & $\begin{array}{l}\text { Contratar um colaborador para ficar responsável pela } \\
\text { organização do estoque }\end{array}$ \\
\hline WHO & Quem fará? & Proprietário/Colaboradores \\
\hline WHERE & $\begin{array}{l}\text { Onde será } \\
\text { feito? }\end{array}$ & Na própria empresa. \\
\hline WHEN & $\begin{array}{l}\text { Quando } \\
\text { fazer? }\end{array}$ & De imediato \\
\hline WHY & $\begin{array}{l}\text { Por que será } \\
\text { feito? }\end{array}$ & $\begin{array}{l}\text { Assim não haverá necessidade de outros colaboradores } \\
\text { deixarem suas funções para cuidar do estoque. }\end{array}$ \\
\hline
\end{tabular}




\begin{tabular}{|l|l|l|}
\hline HOW & Como fazer? & $\begin{array}{l}\text { Divulgar a vaga de auxiliar de estoque nos meios de } \\
\text { comunicação. O Gerente de produção deve selecionar } \\
\text { os currículos seguindo o perfil solicitado pelo mesmo. }\end{array}$ \\
\hline HOW & $\begin{array}{l}\text { Quanto } \\
\text { MUCH }\end{array}$ & $\mathrm{R} \$ 1.200,00$ \\
\hline
\end{tabular}

Fonte: Elaborado pelas autoras do Projeto, 2020.

Sem uma pessoa específica para essa função, os demais colaboradores acabam por deixar suas próprias funções para entrar em contato com essa parte de estoque. Com a falta desse controle, a empresa acaba muitas vezes perdendo serviços e o prazo de entrega aos clientes, o que gera uma insatisfação. Por esse motivo, muitas vezes a empresa acaba adquirindo peças com fornecedores locais.

O colaborador que ficará responsável pelo estoque terá a tarefa de formular um inventário para que se tenha o domínio de todos os produtos em estoque e o volume dos mesmos, assim gerando um melhor atendimento tanto em entregas com prazos ou a pronta entrega.

\section{CONSIDERAÇÕES FINAIS}

A análise feita na empresa lbtech possibilitou observar os demonstrativos da baixa eficiência na área de Operações coletados através de questionaria aplicados na organização. Dessa forma, os meios de melhorias foram buscados para tornar mais eficiente o meio operacional, usando soluções aplicadas através da implantação de ferramentas da qualidade.

Pode-se observar que o principal objetivo do trabalho foi aprimorar o controle do estoque, usando o Ciclo PDCA e também as ferramentas da qualidade 5W2H e 5S.

As ferramentas aplicadas para a administração de melhorias na empresa, devem ser usadas para o controle de todos os movimentos das operações, tendo domínio das necessidades da empresa Ibtech e participação desde as compras, até as vendas, para que assim não se perca o controle dos mesmos. 
O ciclo PDCA usado como a ferramenta principal será utilizado para aumentar a produtividade da empresa, além de ser utilizada para o controle de melhoria. Dessa forma promovendo melhoria contínua nos processos da empresa.

A 5W2H terá como tarefa organizar a área de estoque que encontrasse como uma área crítica da empresa, tendo assim o objetivo de aumentar a lucratividade da empresa, evitando perdas. Por fim será aplicado a ferramenta 5S que também terá seu foco no estoque usada para melhorar o espaço de estocagem, tanto visualmente, como também espacialmente.

\section{REFERÊNCIAS BIBLIOGRÁFICAS}

ARAÚJO, Bruno. 6 formas de melhorar seus canais de distribuição. Disponível em: <https://maximatech.com.br/canais-de-distribuicao/> Acesso em: 17 out. 2020.

DIAS, M. A. P. Administração de materiais: uma abordagem logística. 5. ed. São Paulo: Atlas, 2016.

DORNIER. Logística e Operações Globais. São Paulo: Atlas, 2012.

GIL, M. Metodologia científica. São Paulo: Atlas, 2017.

LAKATOS, Eva Maria e MARCONI, Marina de Andrades. Fundamentos de metodologia científica. 8. ed. - São Paulo: Atlas, 2017.

LIMA, Joilson Souza de. O Planejamento Estratégico como Ferramenta de

Gestão. Revista Científica Multidisciplinar Núcleo do Conhecimento. Ano 3, ed.

03, V. $\quad 03, \quad$ março 2018.

Disponível em:https://www.nucleodoconhecimento.com.br/administracao/planejame nto-estrategico Acesso em: 17 out. 2020.

LIANE Carly Hermes Z. Metodologia de pesquisa. Ed. Reimp. Florianópolis, 2013. 
SEVERINO, A. Metodologia do trabalho científico. 23. ed. rev. e atual. São Paulo: Cortez, 2013.

VALENTE, Amir Mattar; PASSAGLIA, Eunice; Novaes, Antonio Galv ão. Gerenciamento de transporte e frotas. São Paulo: Pioneira Thomson Learning, 2003

Disponível

em<https://issuu.com/cengagebrasil/docs/9788522125142_gerenciamento_transpo> Acesso em: 19 out. 2020.

VERGARA, Sylvia Constant. Projetos e relatórios de pesquisa em administração. São Paulo, 9.ed. Atlas, 2015.

VIANA, J. Administração de Materiais. São Paulo: Atlas, 2015.

VIEIRA, Flávia R. C. Dimensões para o diagnóstico de uma gestão estratégica voltada para o ambiente de empresas de pequeno porte. Florianópolis, 2002. Tese (Doutorado) - Programa de Pós-graduação em Engenharia de Produção, Universidade Federal de Santa Catarina, 2014.

Enviado: Outubro, 2020.

Aprovado: Novembro, 2020. 